OPEN ACCESS

Edited by:

Qingzhao Kong,

Tongji University, China

Reviewed by:

Venu Gopal Madhav Annamdas,

Continental, Germany

Ping Zhao,

University of Minnesota Twin Cities,

United States

*Correspondence:

Junwu Dai

junwu@iem.ac.cn

Specialty section:

This article was submitted to

Smart Materials,

a section of the journal

Frontiers in Materials

Received: 11 June 2021

Accepted: 13 September 2021

Published: 27 September 2021

Citation:

Jiang J, Chen Y and Dai J (2021) Old -

New Concrete Interfacial Bond Slip Monitoring in Anchored Rebar Reinforced Concrete Structure Using

PZT Enabled Active Sensing.

Front. Mater. 8:723684.

doi: 10.3389/fmats.2021.723684

\section{Old - New Concrete Interfacial Bond Slip Monitoring in Anchored Rebar Reinforced Concrete Structure Using PZT Enabled Active Sensing}

\author{
Jian Jiang ${ }^{1,2,3}$, Yixuan Chen $^{2}$ and Junwu Dai ${ }^{1 *}$ \\ ${ }^{1}$ Institute of Engineering Mechanics, China Earthquake Administration, Key Laboratory of Earthquake Engineering and \\ Engineering Vibration, China Earthquake Administration, Harbin, China, ${ }^{2}$ Hubei Key Laboratory of Earthquake Early Warning, \\ Institute of Seismology, China Earthquake Administration, Wuhan, China, ${ }^{3}$ Wuhan Institute of Earthquake Engineering Co. Ltd., \\ Wuhan, China
}

Post-installed anchor technology is widely used for structural strengthening and for retrofitting existing constructions. The old-new concrete interface associated with using this technology is of great significance in the shear capacity of concrete structural member under shear forces. For such members, interface failures usually occur with bond slip. In this paper, an application of a piezoceramic enabled active sensing technique is put forward to monitor Old - New concrete interfacial bond slip. Three concrete specimens (S1, S2, and S3) are fabricated and each specimen consists of two parts. Each part is made of concrete poured at different times, and both are bonded with an anchored rebar embedded inside the specimen. Two PZT aggregates bonded to opposing sides of the concrete specimen helped to realize active sensing. During the shear loading test, both the load values and the signals from sensors are acquired every $20 \mathrm{~s}$. The test durations of S1, S2 and S3 lasted 960, 1,120 , and $1,110 \mathrm{~s}$, respectively. Furthermore, the received signal energies are quantified through wavelet packet analysis to monitor the Old - New concrete interfacial bond slip process. The experimental results show that the change of WPEl in the received signals has a direct relation with the severity of the Old New concrete interfacial bond slip. Moreover, the PZT-based active sensing approach is feasible to monitor the shear-induced bond slip in Old - New concrete interfaces.

Keywords: anchored rebar, bond slip, lead zirconate titanate transducer, active sensing, structural health monitoring

\section{INTRODUCTION}

Post-installed anchor technology has been commonly applied in terms of structural strengthening and retrofitting of existing constructions. A post-installed anchor in general is composed by a rebar imbedded in a hole drilled in hardened concrete with structural bonding agent (Cook, 1992; Cook et al., 1993; Ronald and Robert, 2001). Currently, epoxy acts as an universal structural adhesive due to its excellent properties (Wang et al., 2015). Since the rebars can be installed in nearly all the expected position in hardened concrete, the post-installed anchors are able to increase the whole 
framework's bearing capacity by integrating the new concrete member with the original concrete member (Wörle, 2014).

As the post-installed anchor technique serves as a connection method of high efficiency in terms of structural reconstruction and expansion, now it has been widely applied in practice and has also attracted much research attention. Much of the reported research literature focus on interfaces in rebar, epoxy, and concrete systems (Mahrenholtz et al., 2016; González et al., 2018; Muciaccia et al., 2018). Bouazaoui and Li (2008) used pull out tests to investigate the interfacial adhesion quality between rebar and concrete as well as to measure the apparent shear stress between anchored rebar and concrete. Barnaf et al. (2012) carried out the pull out tests and numerical simulations so as to determine both the behavior and bonding strength of industrial adhesives which are adopted for anchor bonding. Bajer and Barnat (2012) conducted researches over both the bond quality and the concrete-bond failure of a bonded anchor loaded by tensile forces. The pull-out test is commonly introduced to check the bonding strength between concrete and anchored rebar systems; nevertheless, pull-out tests are detrimental (Yilmaz et al., 2013; Brencich, 2015). Nondestructive evaluation (NDE) methods are generally required for the purpose of performing in-situ assessment over epoxy bonded anchors. Rizzo et al. (2010) studied the adoption of acoustic emission (AE) to evaluate the structural stability of concrete strengthened and underpinned by chemically bonded anchors.

Moreover, the PZT-enabled active sensing approach was introduced by Jiang et al. (2019) to demonstrate the development of bonding strength along the interface layer between the concrete and the bonded rebar. The $\mathrm{AE}$ parameters including the amplitude, duration, and signal strength were employed to characterize the stage of concrete bond deterioration (Abouhussien and Hassan, 2017b). Hou et al. (2009) discussed the feasibility of OTDR optical fiber technology to monitor the debonding of FRP reinforced concrete structure. Zhou et al. (2008) used BOTDR(A) technology to evaluate the bond slips between steel bars and concrete in reinforced concrete beams. In addition, electro-mechanical impedance (EMI) method was employed to detect the bond-slip in the concrete-encased composite structure (Liang et al., 2016).

However, the shear bearing capacity of a strengthened member is collectively assumed by the concrete and the anchored rebars when the member is under shear load. The interface between the new and old concrete is relatively weak due to the discontinuous aggregate particles in the Old - New concrete interface caused by the different pouring time (Maili and Jing, 2018). Therefore, the Old - New concrete interface plays a crucial role in determining the shear bearing capacity; specifically, interface failures usually occur with bond slip. To prevent the brittle and sudden failure of strengthened concrete structures, it is of practical significance and great research value to monitor the bond slip at the Old - New concrete interface when a strengthen structural member is under shear load. Most studies mainly focus on the effect of shear force on the interfacial bond slip of new-old concrete. In Wang's research, theoretical and experimental research was performed to evaluate the mechanical performance of new and old concrete beams under sustained loads (Wang et al., 2011). As to find out the influencing factors on the bond slip, the age difference (Song et al., 2015), normal stresses (Al-Fasih et al., 2021) and curing condition (Mirmoghtadaei et al., 2015) were considered. Many studies have also shown that the concrete type has a certain influence on the interfacial bond slip between the Old - New concrete. In their researches, concrete types include: reinforced concrete (Abouhussien and Hassan, 2017), high-strength concrete (Qasim, 2020), ultra-high-strength (Hyun-Soo Youm and Changbin, 2021), composite ceramist lightweight aggregate concrete (Liu et al., 2020), and reactive powder concrete (Ju et al., 2020). In addition, the influence of compressive strength on the bond slip of the old-new concrete were evaluated and the optical compressive strength were concluded (Júlio et al., 2006; Diab et al., 2017). Recently, the scanning electron microscopy (SEM) were employed to evaluate the interfacial bond properties of self-expanding polymer and concrete under the shear load (Fang et al., 2021).

In recent years, the piezoelectric-based technique has been commonly accepted and applied as an effective form of structural health monitoring (SHM) technique (Bhalla and Kaur, 2018; Feng and Ou, 2018; Hu et al., 2018; Xu et al., 2019). Serving as one of the most commonly recognized piezoelectric materials, Lead Zirconate Titanate (PZT) has the advantages of low costs, quick response, and wide bandwidth (Zhu et al., 2017; Zhou et al., 2020), and can be easily fabricated in different geometries (Zeng et al., 2015; Wang et al., 2020a). Because of the piezoelectric effect, PZT patches can be used as either sensors or actuators for structural damage detection and condition monitoring (Nicassio et al., 2020). Most of the early applications of PZTbased techniques are based on impedance analysis and active sensing. For example, impedance analysis was adopted in order to evaluate debonding between fiber-reinforced polymer rebar and fiber-reinforced polymer rebar (Li et al., 2017), preload monitoring in bolted connections (Lee, 2021), load monitoring (Annamdas and Soh, 2017), damage monitoring in pin connection (Fan et al., 2018), and monitoring the status of a composite panel (Dziendzikowski et al., 2018). The active sensing technique was used for cement hydration monitoring (Kong and Song, 2017), impact localization (Coles et al., 2020), monitoring of bolted spherical joint connections (Xu et al., 2018a), timber crack monitoring (Wang et al., 2020b) and cyclic crack monitoring (Qin et al., 2015).

Active sensing technology was also applied for detecting and monitoring the structural bond slip, which includes but not limited to the bond slip detection between concrete and a steel plate (Xu et al., 2018b; Feng and Ou, 2015), the bond slip between concrete and GFRP/steel bars (Hong et al., 2018; Zhang et al., 2020), and the debonding detection in hidden frame supported glass curtain walls (Kong et al., 2016). However, to the authors' best knowledge, no literature is available about active sensingbased monitoring of Old - New concrete interfacial bond slip in post-installed anchor reinforced structures. Therefore, this paper conducts experiments to detect the Old - New concrete interfacial bond slip using the method of PZT-based active sensing. To demonstrate whether the PZT enabled active sensing approach is 

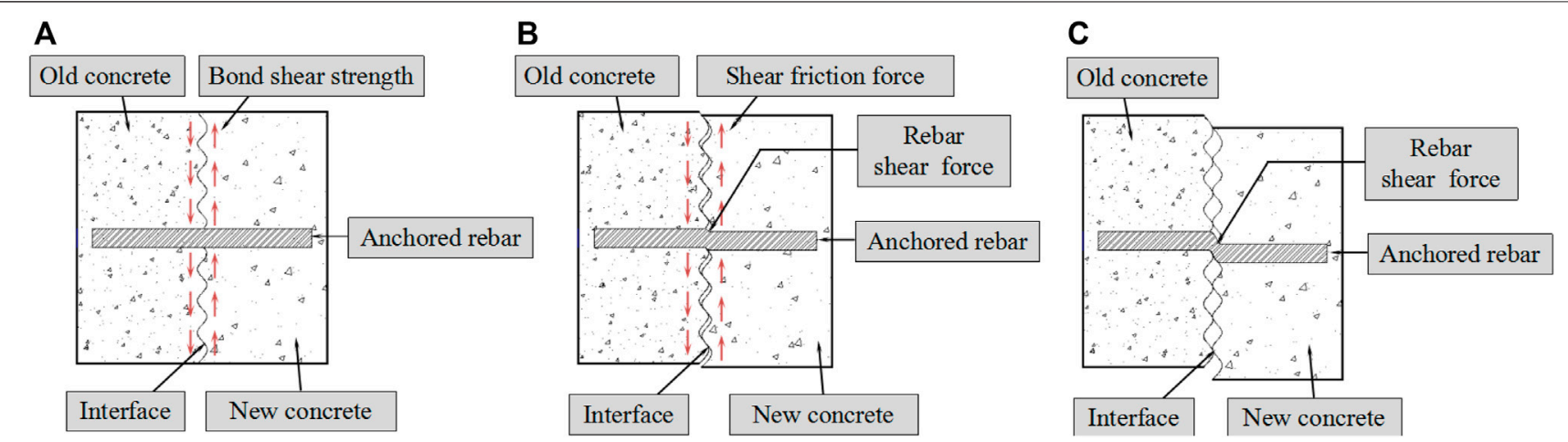

FIGURE 1 | The Old - New concrete interfacial bond slip process of the anchoring specimen: (A) Force state diagram of interface before bond slip; (B) Force state diagram after interfacial bond slip; (C) Force state diagram after interface separation.

feasible or not, three testing specimens are fabricated, with each specimen containing two sections of concrete that are respectively poured at two different times. An anchored rebar is installed in both the new and the old concretes. Two PZT aggregates severed as an actuator-sensor active sensing pair to monitor the Old New concrete interface bond slip when the specimens experienced shear loads applied a by test machine. The experimental results show the development of bond slip at the interface between the new and old concrete with the shear loading procedure, and that the bond slip influences the interface shearing capacity and the stress wave propagation. The comparison between the load-time curve and the WPEI - time curve demonstrates that the active sensing method is an effective approach to detect the bond slip processes in Old - New concrete interfaces.

\section{PRINCIPLES}

\section{Analysis of Old - New Concrete Interfacial Shear Mechanism}

The Old - New concrete interfacial bond slip mechanism of the anchoring specimen can be segmented into three stages as seen in Figure 1. As shown in Figure 1A, from the beginning of loading until the occurrence of Old - New concrete interfacial bond slip, the shear capacity attributes to the adhesive force of the concrete. At this stage, the bond is composed by van der Waals forces, the chemical strength of the cement base, and the mechanical bite ability of the Old - New concrete aggregate (Maili and Jing, 2018). When a sufficiently strong shear force occurs, the interfacial bond slip can be witnessed, which begins as a small crack at the interface. With the continuously increasing shear force, the crack continues to grow until it spans the entire interface, as shown in Figure 1B. At this stage, the anchored rebar begins to partake remarkably during the interfacial shear process. The interfacial shear capacity mainly stems from the frictional force of concrete as well as the shear force of the anchored rebar. After the interface is separated, as shown in Figure 1C, the bite force of the Old - New concrete interface is observed a decline to zero, and the shear capacity is entirely born by the pinned rebar.

\section{Piezoceramic-Based Active Sensing Method}

Figure 2 illustrates the active sensing method for monitoring Old New concrete interfacial bond slip within an anchored rebar reinforced concrete structure during the shearing test process. Two PZT aggregates are attached on the new and old concrete surfaces, respectively. One PZT aggregate participates as an actuator and another plays a role as a sensor. The propagation of the stress wave originated from the actuator can be clearly witnessed from the old concrete to the new concrete through the interface and the anchored rebar. The sensor is capable of detecting the stress waves propagating from the new concrete since concrete participates significantly as a desirable conduit for the propagation of the stress wave. During the interfacial bond slip monitoring test, the stress waves propagation is highly dependent upon the bond condition of the Old - New concrete interface. From the beginning of loading until the initiation of the interfacial bond slip, the performance of the new-old concrete bond is pretty excellent. The stress wave can easily travel through both sections of concrete and be received by the sensor with minimal distortion. when the shear force increases to a specific high level and relative interfacial sliding occurs, the crack between new and old concrete will exert a direct influence on the propagation of the stress wave. With further interfacial bond slip, the stress wave energy spread from the old concrete to the new one continues to attenuate. The stress wave energy decreases towards a steady state as the crack completely separates the interface. When the interface is completely separated, only a minimal amount of stress wave energy is propagated through the anchor rebar still connecting the two sections of concrete. With the analysis of the received signals' energy, the Old - New concrete interfacial bond slip process can be monitored.

\section{Wavelet Packet-Based Energy Index}

The wavelet packet-based energy index (WPEI) is an effective analysis technique that has been widely used to quantitatively evaluate structural changes. In this study, the stress-wave energy transmission from the old concrete to the new concrete is sensitively correlated to the performance of interface bond; thus, the energy response which is observed and noted at the 


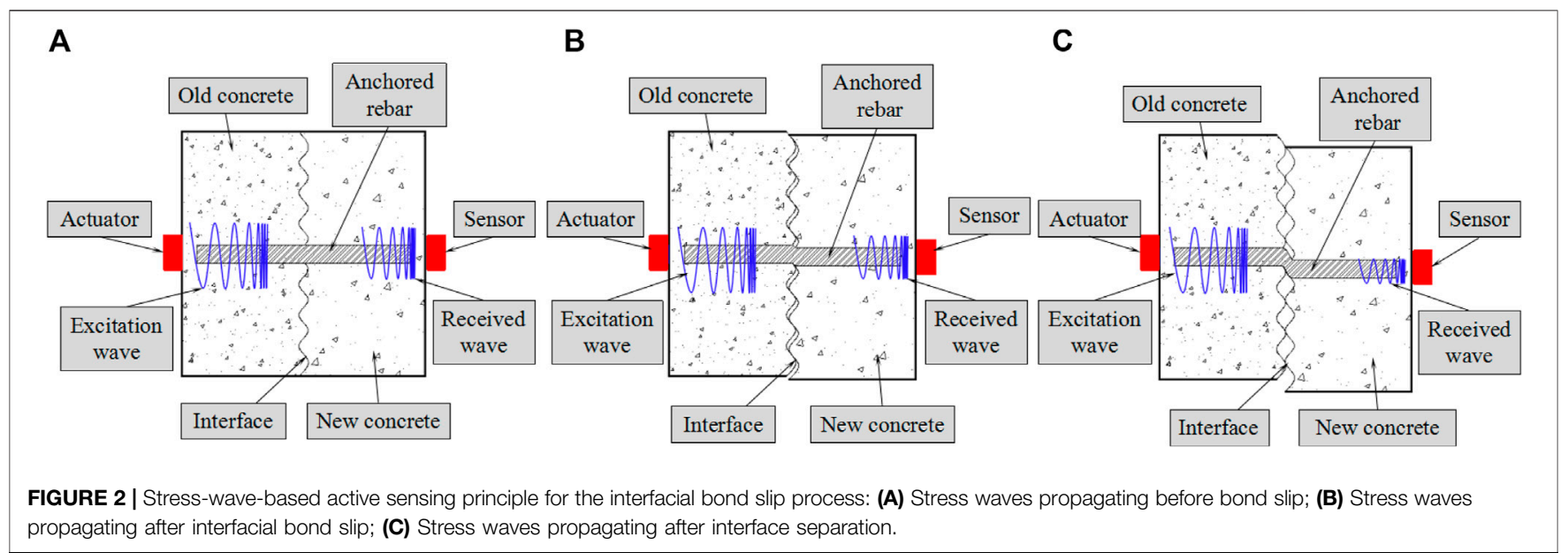

sensor can indicate and gauge the bond condition and even the bond slip process. In order to monitor the stress waves' energy recorded at PZT sensors, WPEI analysis is introduced herein to compute the energy values of the signal at PZT sensors. Because the received sensor signal is a frequency rich wave that is correlated to the actuator's production, the sweep sine wave excitation signal, WPEI analysis can be utilized in the decomposing of the recorded wave into a series of frequency bands. The total energy of the received stress wave signal can be estimated by the summation of energies across all the frequency bands.

The PZT sensor signal that represents the propagation stress wave is decomposed through wavelet packet decomposition. Here a n-level decomposition is assumed, which will result in $2^{n}$ signal sets $\left\{X_{1}, X_{2}, \ldots, X_{2^{n}}\right\}$. Furthermore, $\mathrm{j}$ is assumed to be the frequency band, with $\mathrm{j}=1,2, \ldots, 2^{\mathrm{n}}$ and $\mathrm{n}=5$ in this study. Each decomposed signal from the original signal $\mathrm{X}_{\mathrm{j}}$ can be further defined as following:

$$
X_{j}=\left[x_{j, 1}, x_{j, 2}, \ldots, x_{j, m}\right]
$$

where $m$ refers to the number of samples. Thus, the decomposed signal energy $\mathrm{E}_{j}$ can be specifically expressed as:

$$
\mathrm{E}_{\mathrm{j}}=\sum_{k=1}^{\boldsymbol{k}=m} x_{j, k}^{2}
$$

The total energy of the stress wave signal E can be summarized by all the decomposed signals and expressed as:

$$
E=\sum_{j=1}^{2^{n}} E_{j}
$$

The recorded signal can be characterized based on the WPEI analysis. In this experiment, the Old - New concrete interface bond condition at the beginning of the shear loading test is recognized as the original state. The received signal energy decreases with the worsening of interfacial bond slip, and the WPEI computes the changes in the received signal energy during the shear loading test.

\section{EXPERIMENTAL SETUP AND PROCEDURE}

\section{Specimen Fabrication}

In the experiment, three specimens (S1, S2, and S3) with the same dimensions and materials were fabricated. Each specimen consists of three parts: old concrete, new concrete and an anchored rebar. Figure 3 details the fabrication process and the dimensions of the specimens. Firstly, the first (i.e., old) layer of class C25 concrete with the dimensions $160 \mathrm{~mm} \times$ $160 \mathrm{~mm} \times 80 \mathrm{~mm}$ was poured. In the specimen, the part of old concrete is first poured and set for 28 days. Then, the rebar was implanted into a hole drilled into the old concrete and secured in place using epoxy. After the epoxy completely solidified for few hours, the new concrete of class C35 was poured over the old concrete. After the new concrete has solidified with another 28 days, the specimens are formed and conducted the experiments. The dimensions, strength grade and implanted length of the rebar are $\Phi 14 \mathrm{~mm} \times 140 \mathrm{~mm}, \mathrm{HRB} 335$ and $70 \mathrm{~mm}$, respectively.

As vividly illustrated in Figure 4, two PZT aggregates are firmly adhered to the surfaces of new and old concrete. One of them participated as the actuator and the other one worked as the sensor in the monitoring test. The aggregate is composed by inserting a PZT patch with electric wire into two cylindrical marble blocks. The dimensions of the cylindrical smart aggregate and the PZT patch are $\Phi 25 \mathrm{~mm} \times 20 \mathrm{~mm}$ and $15 \mathrm{~mm} \times 15 \mathrm{~mm} \times$ $0.3 \mathrm{~mm}$, respectively. The material properties of the experimental specimens and PZT aggregates are listed in Table $\mathbf{1 .}$

\section{Experimental Setup}

Figure 5 illustrates the experimental setup for the monitoring of the Old - New concrete interfacial bond slip. The setup includes the specimens (S1, S2, and S3) with PZT aggregates, a power amplifier, a data acquisition and control system, and a laptop computer. To excite the PZT actuator, a swept sine wave signal is initially produced by the data acquisition and control system and then augmented by the power amplifier with a gain of 50 . Then the amplified swept sine signal is fed into the actuator to produce the stress wave, and the sensor detected the propagating wave 


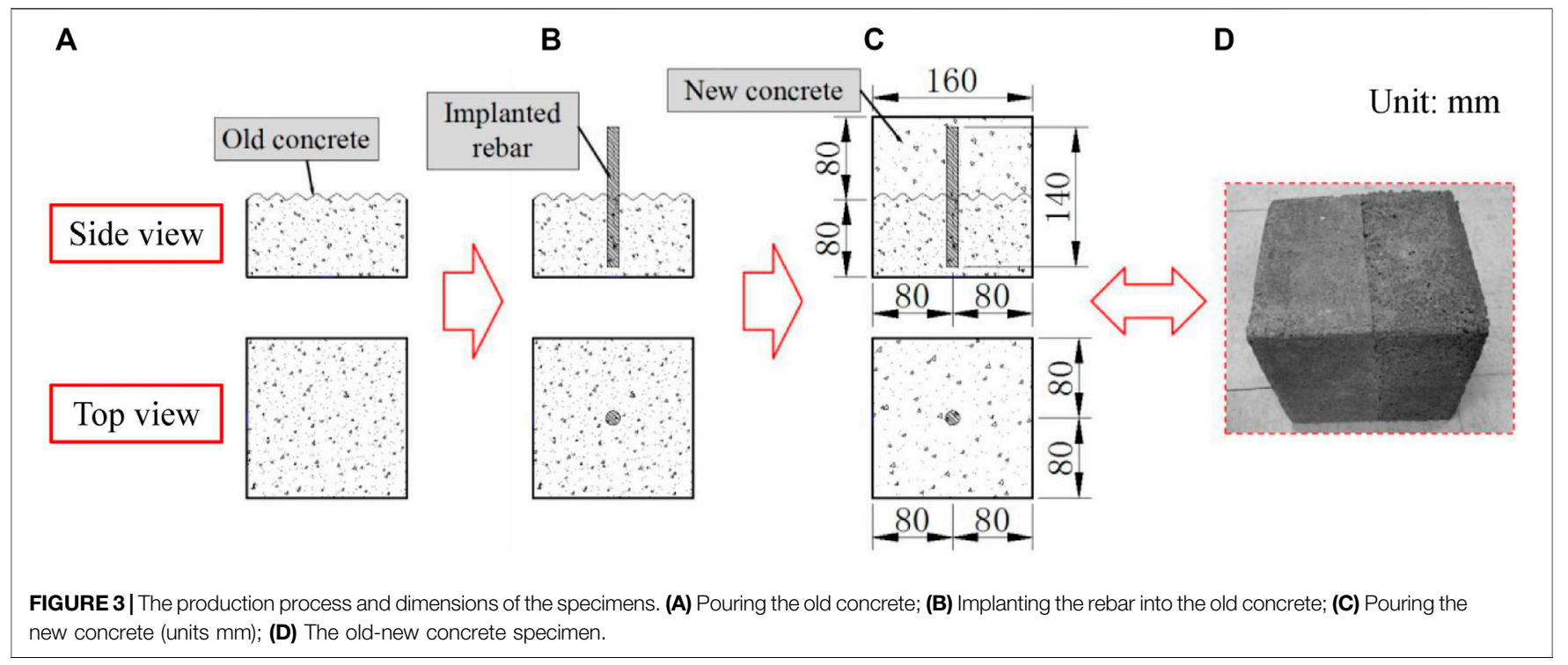

A

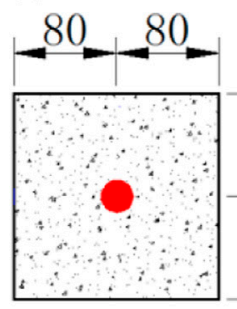

B

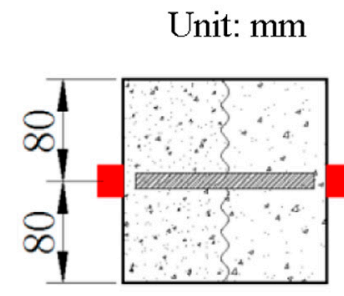

C

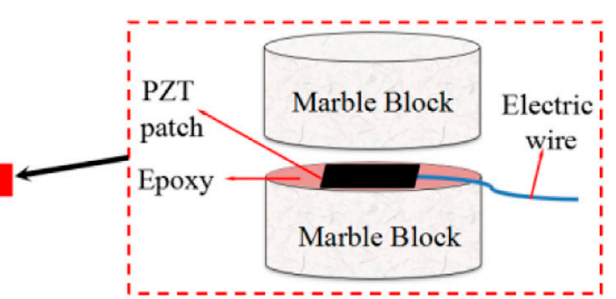

FIGURE 4 | The position and structure of PZT aggregates. (A) The top view of the specimen; (B) The front view of the specimen; (C) The profile of PZT aggregates. (units $\mathrm{mm}$ ).

TABLE 1 | The material properties of the experimental specimens.

\begin{tabular}{|c|c|c|c|}
\hline Materials & Parameters & Value & Units \\
\hline \multirow[t]{3}{*}{ Concrete } & Density & 2,400 & $\mathrm{~kg} / \mathrm{m}^{3}$ \\
\hline & Young's modulus & 33 & Gpa \\
\hline & Compression strength & 40.3 & Mpa \\
\hline & Yield strength & 350 & Mpa \\
\hline & Tensile strength & 530 & Mpa \\
\hline & Elongation & 19 & $\%$ \\
\hline & Flexure strength & 53 & Mpa \\
\hline & Bonding strength & 17 & Mpa \\
\hline \multirow[t]{2}{*}{ PZT aggregates } & Dimension & $\Phi 25 \times 20$ & $\mathrm{Mm}$ \\
\hline & Piezoelectric strain coefficients (-d31/d33/d15) & $1.75 / 4.00 / 5.90$ & $10-10 \mathrm{C} / \mathrm{N}$ \\
\hline
\end{tabular}

from concrete. For the swept sine signal, the frequency range is $1,000 \mathrm{~Hz}-300 \mathrm{kHz}$, the amplitude is $3 \mathrm{~V}$, and the time interval is $1 \mathrm{~s}$. The sampling frequency of the data acquisition and control system is $2 \mathrm{MS} / \mathrm{s}$.

In the experiment, the axial compressive load adopted upon the specimen is under the control of a universal material test machine under the displacement control mode, as shown in Figure 5. In order to apply a uniform stress to the specimen, two thick steel plates were placed at the upper and lower ends of the specimen, respectively. Furthermore, two steel blocks and two wood blocks were placed between the test specimen and thick steel plates, and the specific position of the blocks are shown in 


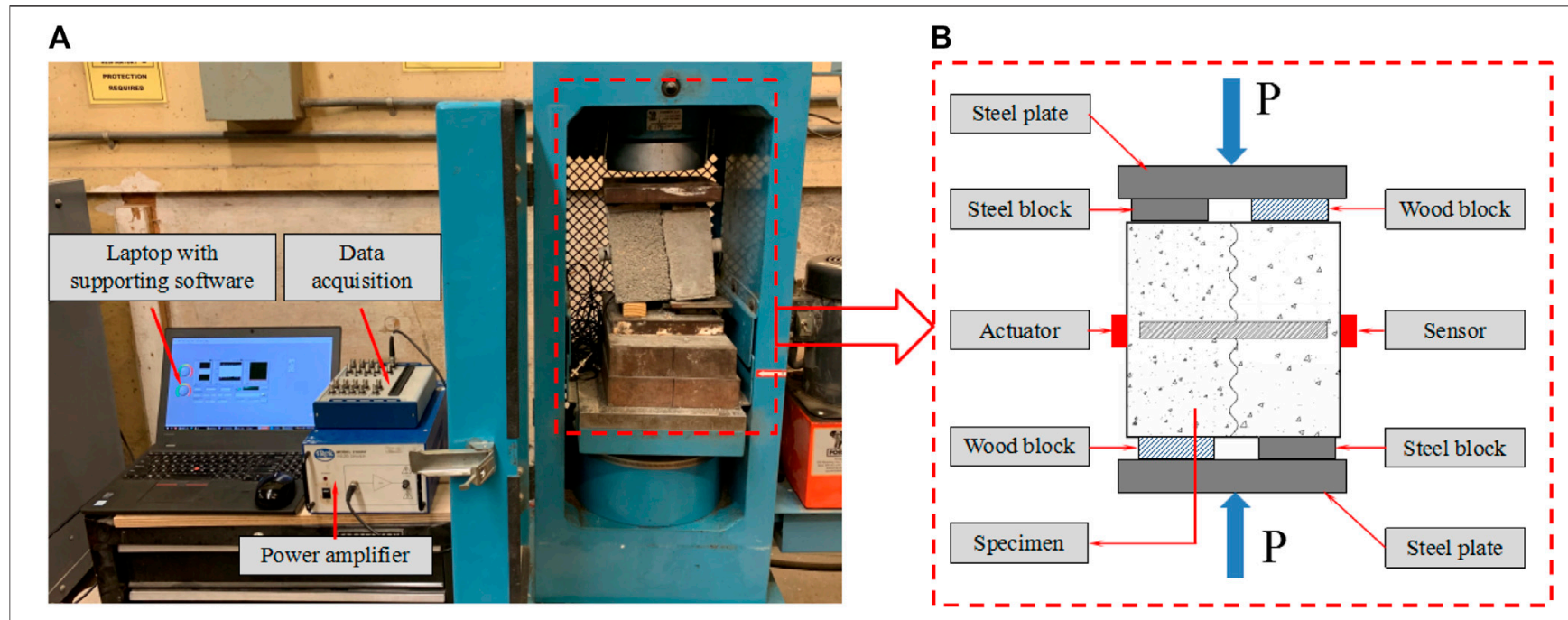

FIGURE 5 | Experimental setup of the experimental test. (A) The overall diagram of experimental setup; (B) The details of the spencimen in the experimental setup.

Figure 5. It is noted that the position of wood blocks and steel blocks in the upper and lower ends of the test specimen is different. When the vertical load was set upon the central position of the steel plate by the hydraulic machine, compressive stress is applied to the old-new concrete specimens through the wood and iron blocks. Due to different Young's modulus between the wood and iron blocks, they will produce different compression deformation. Different deformations of the blocks can lead to different vertical displacement of old and new concrete, resulting in shear forces at the Old - New concrete interface. Before the concrete interface is stripped, the specimen is not deformed, two thick steel plates have a strong binding force at the upper and lower ends of the test specimen, resulting in good shear force conduction at the interface.

In terms of both the PZT-enabled active sensing and pressure gauge, the load value and received signal were collected every $20 \mathrm{~s}$. During each experiment, the Old - New concrete interfacial bond slip would be eventually accompanied by a visible crack and a shear displacement, meanwhile, there would be a plunge in the loading time history. When this happened, the experiment was terminated.

\section{EXPERIMENTAL RESULTS AND DISCUSSIONS}

Figure 6 shows the specimens after the shear loading test. A visible crack can be observed in each specimen. The loading time histories of S1, S2, and S3 are respectively represented by the red, black, and blue curves in Figure 7. The load in Figure 7 is the compressive force from the testing system. As explained in Experimental Setup, the process of applying compressive stress in the specimens result in the interfacial bond slip between the old/new concrete. Therefore, the time history curve of the compressive force was employed to reflect the interfacial bond

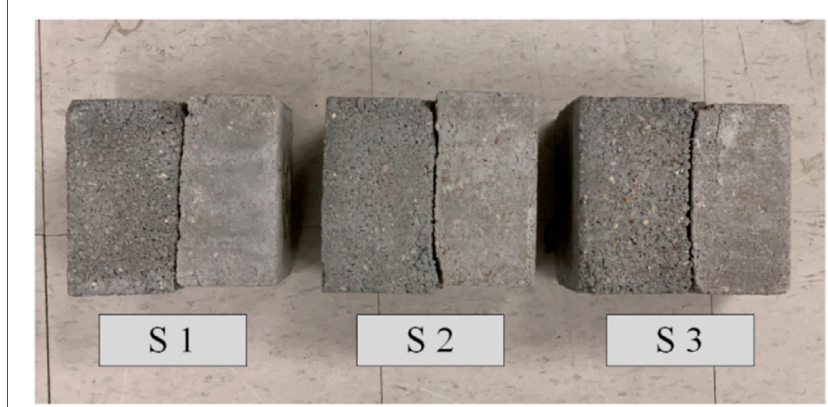

FIGURE 6 | Specimens after shear loading test.

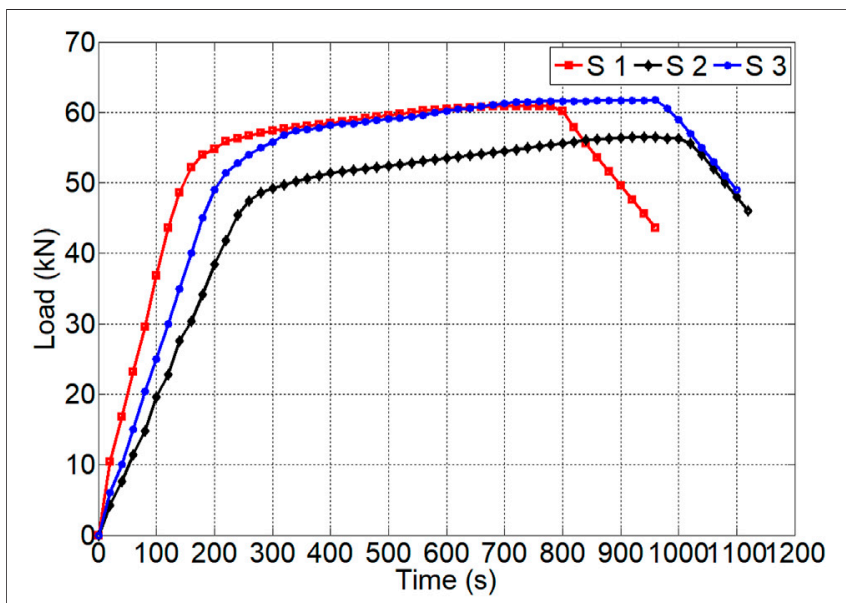

FIGURE 7 | Load-time relationship of specimens during shearing test.

slip process of the old/new concrete. The test durations of S1, S2, and S3 are respectively $960,1,120$, and $1,110 \mathrm{~s}$. It is clearly illustrated from the red curve that there are three stages in the 

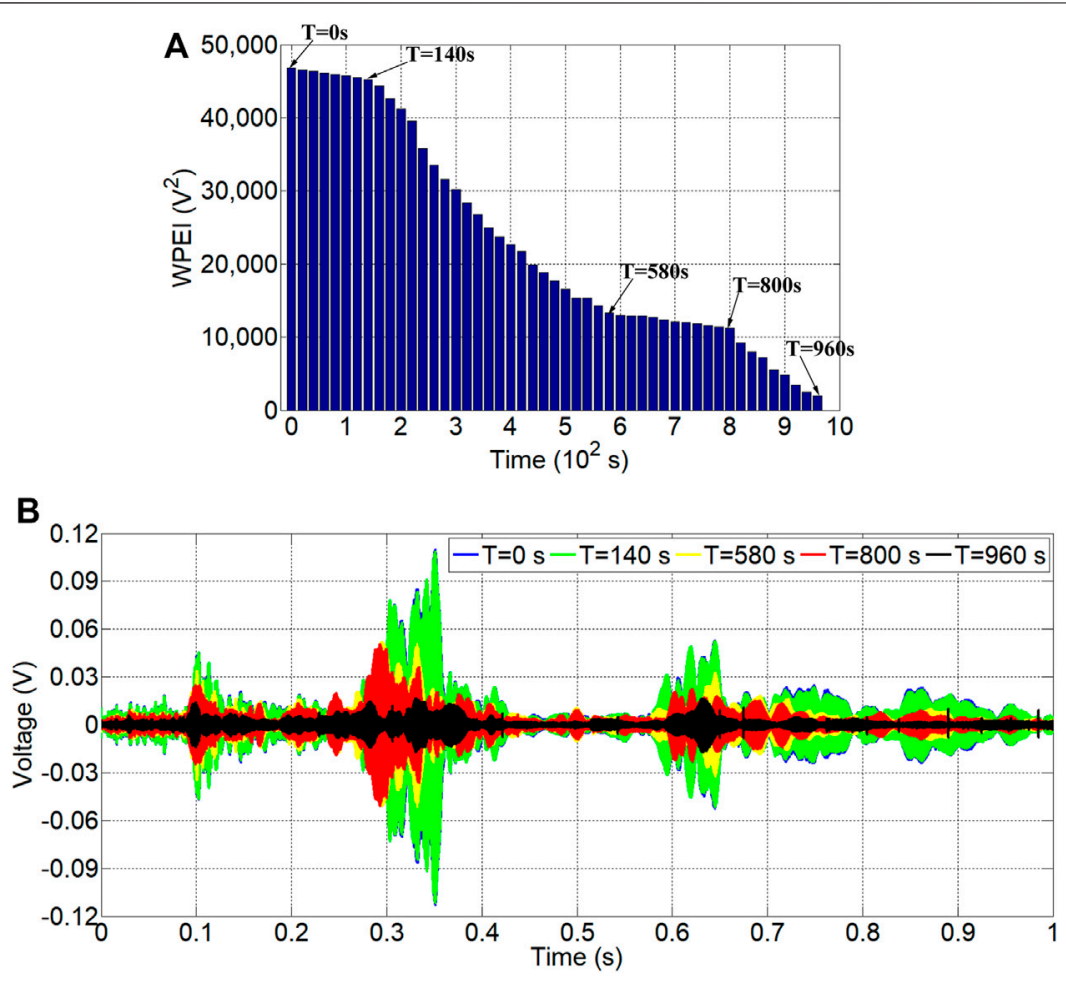

FIGURE 8 | WPEls and received signal of S1: (A) WPEls of the received signal; (B) the received stress wave signal.

loading process. From $0 \mathrm{~s}$ to $140 \mathrm{~s}$, the shear strength of the newold concrete interlayer is generated by the concrete's bond strength. In this stage, the load value increases rapidly and linearly with time. From $140 \mathrm{~s}$ to $800 \mathrm{~s}$, the interfacial shear capacity is significantly produced by both the concrete. frictional force of the concrete and shear force of anchored rebar. At this point, the load rate slowed down significantly. From $580 \mathrm{~s}$ to $800 \mathrm{~s}$ the load value remained almost a constant value. From $800 \mathrm{~s}$ to $960 \mathrm{~s}$, visible cracks appeared in the interface between old and new concrete. In this stage, the interlayer shear strength is mostly generated by the shear force of anchored rebar and the load value drops rapidly. The maximum load value of S1 is $60.42 \mathrm{kN}$. S2 and S3 can also be divided into three stages of the same trend (black curve at $0-240 \mathrm{~s}, 240-1,020 \mathrm{~s}$, and $1,020-1,120 \mathrm{~s}$; blue curve at $0-220 \mathrm{~s}, 220-980 \mathrm{~s}$, and $980-1,110 \mathrm{~s})$. The maximum load of S2 is 56.50 and $61.74 \mathrm{kN}$ for S3.

The received signal was recorded every $20 \mathrm{~s}$ during the experiment. Figure 8A shows the WPEIs of received signals of S1 during the shear loading process. The WPEIs can be divided into four stages over time: $0-140 \mathrm{~s}, 140-580 \mathrm{~s}, 580-800 \mathrm{~s}$, and 800-960 s. Figure 8B demonstrates the time domain signal collected in S1 at 0, 140, 580, 800, and 960 s. Each curve acts as a representation of the received signal by sensor over a $1 \mathrm{~s}$ duration (i.e., the length of the swept sine signal). The received signals at 0 and $140 \mathrm{~s}$ are almost identical as indicated by the blue curve and green curve in Figure 8B. The WPEI experiences only a slight change in this stage, suggesting that bond slip has not yet occurred and the Old - New concrete interface bond strength can bear the shear load. From 140 to $580 \mathrm{~s}$, the WPEI experiences a notable decrease with time elapsed. The decrease in WPEI is mirror by the drop in the amplitude of the received signals between 140 and $580 \mathrm{~s}$, as seen in the green and yellow curves in Figure 8B. The signal strength reduction means that the Old New concrete interfacial bond slip has occurred and is worsening. From 580 to $800 \mathrm{~s}$, there is little change of in WPEI while the amplitude of the received signals has slight reduction. The lack of significant changes means that the interfacial bond slip has spread throughout the entire interface, but the Old - New concrete interface is not completely separated. From 800 to $960 \mathrm{~s}$, the WPEI continues to decrease towards a very low value. As shown in Figure 8B, this stage is represented by the black curve. and the amplitude of the recorded signal at $960 \mathrm{~s}$ is greatly reduced to less than $0.01 \mathrm{~V}$. In this stage the Old - New concrete interface is beginning to separate, and the stress wave can only propagate through the rebar, explaining the weak received signal. Figures 9 , 10 present that the behavior of the WPEIs and time domain signals of S2 and S3 remain almost the same as that of S1. The WPEIs and the amplitude of the received stress wave signals vary with the deterioration of Old - New concrete interface bond condition.

The relationship between the load and the WPEIs of S1, S2, and $S 3$ are shown in Figure 11. The blue curve represents the load value during the shear loading test and the red curve represents the WPEI of the recorded signals. As clearly illustrated in Figure 11A, in first $140 \mathrm{~s}$, the load value increases linearly and 


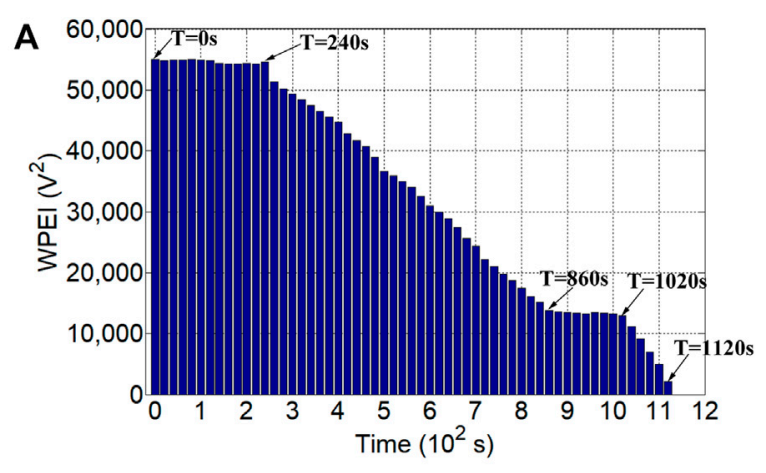

B

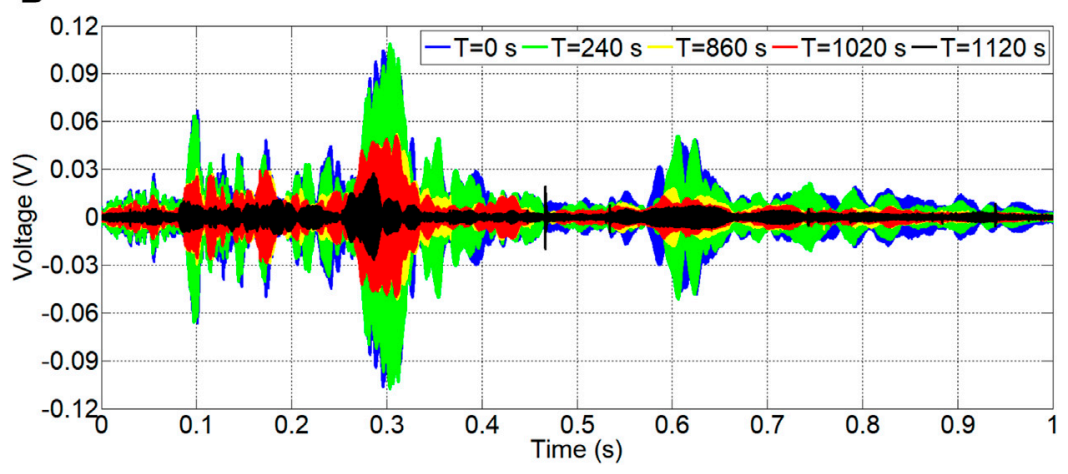

FIGURE 9 | WPEls and received signal of S2: (A) WPEls of the received signal; (B) the received stress wave signal.

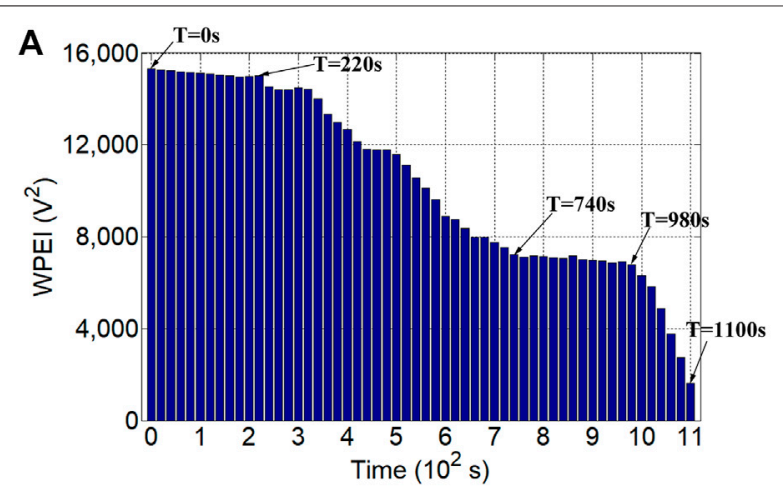

B

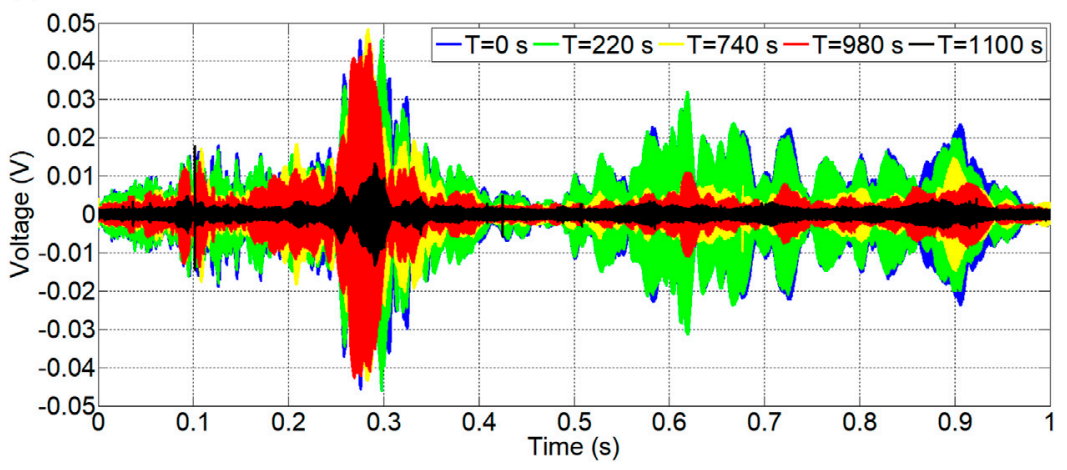

FIGURE 10 | WPEls and received signal of S3: (A) WPEls of the received signal; (B) the received stress wave signal. 

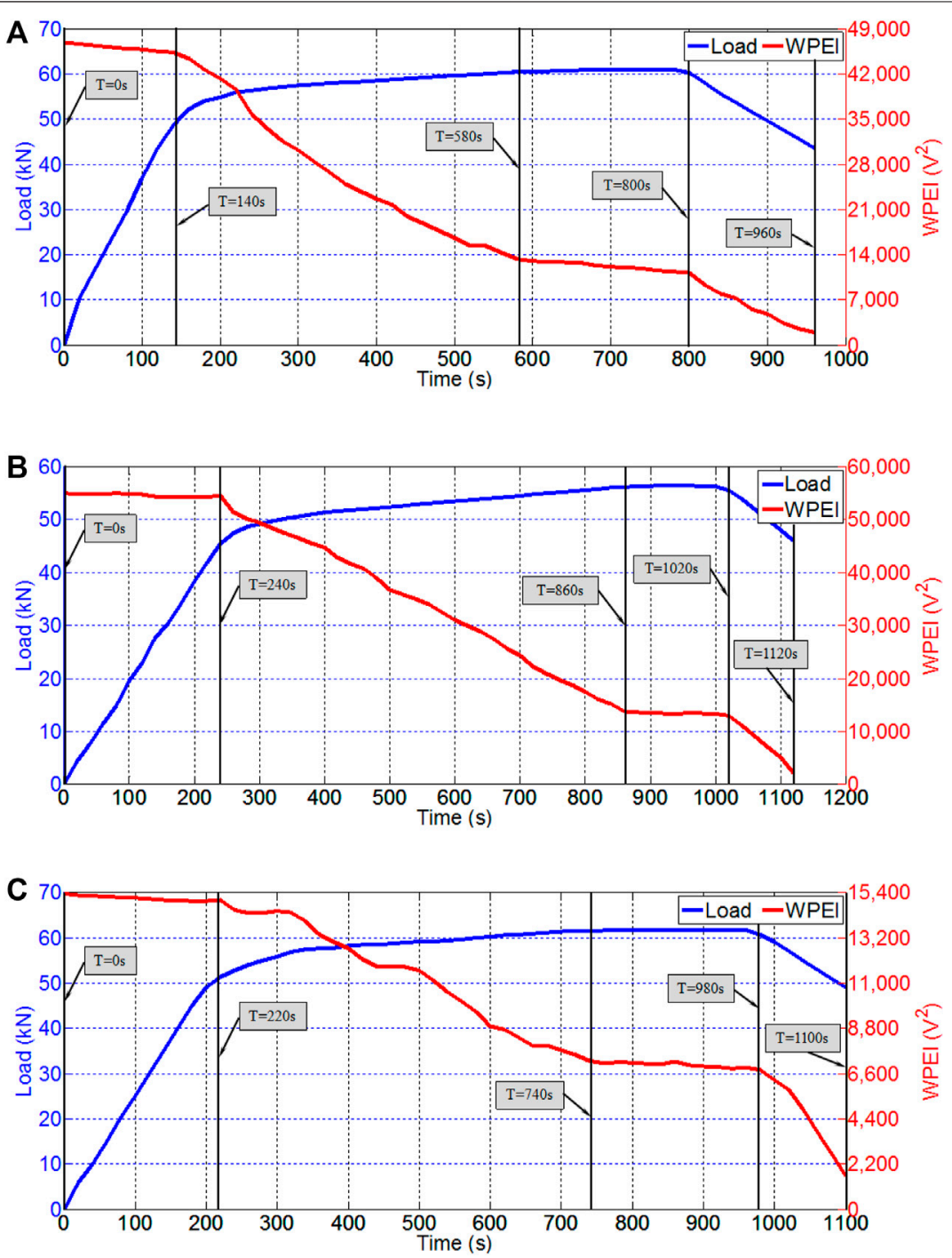

FIGURE 11 | The relationship between load and WPEls for the three different specimens: (A) The relationship between load and WPEls of S1; (B) The relationship between load and WPEIs of S2; (C) The relationship between load and WPEls of S3.

the WPEI value changes slightly, which means that in this stage there is no bond slip at the interface and that the shear capacity is generated by the Old - New concrete bond strength. From 140 to $580 \mathrm{~s}$, the load value increases nonlinearly, and the growth rate decreases. The WPEI decreases significantly in this stage. These changes show that the Old - New concrete interfacial bond slip has initiated and is continuing to develop. In this stage, the anchored rebar begins to play an important role in the shear process of the interface, and the interfacial shear capacity mainly originates from the shear force of anchored rebar and the frictional force of concrete. From 580 to $800 \mathrm{~s}$, the load value reaches a steady-state value and the WPEI value decreases slightly. In this stage, the bond slip continues to develop, and the crack runs throughout the entire interface. However, the Old New concrete interface is not completely separated, and the shear force is shared by both the frictional force of concrete and the shear force of anchored rebar. From 800 to 960 s, both the load and the WPEI experiences an obvious reduction. In this stage, a visible crack and shear displacement in the S1 can be observed. The interface of Old - New concrete began to separate, and the bite force of the interface is reduced to zero. The interfacial shear capacity mainly depends on the shear force of the anchored rebar. Therefore, the stress wave can only travel through the rebar, and the WPEI drops rapidly.

In Figures 11B,C, the load-time curve and WPEI-time curve show share a similar trend as the one shown in Figure 11A. As the Old - New concrete interface is the weakest parts of all the specimens during the shear loading test, the interfacial bond condition varies with increases in applied shear force. The interfacial bond slip occurs when shear force is bigger than the interface bond strength, and stress wave propagation will change. The Old - New concrete interfacial bond slip process can be tracked by the analysis of the collected signal, which illustrates that the method of active sensing is able to effectively detect the 
Old - New concrete interfacial bond slip development in real time during the shear loading process.

In the experiment process, when the interfacial bond slip occurs and concrete tilted, compressive loads may take place at the interface as well. Nevertheless, this paper mainly attempts to employ the piezoelectric active sensing method to monitor the process of interfacial bond slip between the new-old concrete reinforced by the anchored rebar. Although it is likely to result in the compressive loads when the bond slip happened in the newold concrete, the active sensing could effectively characterize the process of the old-new concrete interfacial bond slip. Different from the concrete cube in this paper, the main load-bearing components in the actual project are beams or columns. Therefore, the anchoring form of the steel bar in the new concrete and the layout of the transducers in practical project will also be different from the experimental studies. However, the paper is an exploratory experiment which explore the feasibility of the active sensing method to monitor Old - New concrete interfacial bond slip in the anchored rebar reinforced concrete structure.

\section{CONCLUSION AND FUTURE WORK}

The Old - New concrete interface is the weakest link of concrete structures reinforced with post-installed anchors, especially when under shear loads. Interface failure often initiates with bond slip, and it is necessary to monitor the Old - New concrete interfacial bond slip to avoid the brittle and sudden failure of strengthen concrete structures. A PZT-based active sensing method was developed for the real time monitoring of Old - New concrete interfacial bond slip in a post-installed anchor reinforced concrete structure. To verify the proposed approaches, experiments were conducted upon specimens consisting of two parts of concrete which were poured at different times. The new and old concrete parts were connected with an anchored rebar. Two PZT aggregates were adhered to the two opposing ends of the concrete specimen to realize the active sensing approach. A shear loading test was conducted in which the load value and received signal were collected every $20 \mathrm{~s}$. A comparison of the wavelet packet-based energy index (WPEI) with the load value clearly shows that the interfacial bond condition changes with the shear force development. Interfacial bond slip occurs when shear force is larger than the interface bond strength. Bond slip can

\section{REFERENCES}

Abouhussien, A. A., and Hassan, A. A. (2017). Acoustic Emission Monitoring for Bond Integrity Evaluation of Reinforced concrete under Pull-Out Tests. Adv. Struct. Eng. 20 (9), 1390-1405. doi:10.1177/1369433216678864

Abouhussien, A. A., and Hassan, A. A. (2017). Application of Acoustic Emission Monitoring for Assessment of Bond Performance of Corroded Reinforced concrete Beams. Struct. Health Monit. 16 (6), 732-744. doi:10.1177/ 1475921716681460

Al-Fasih, M. Y., Mohamad, M. E., Ibrahim, I. S., Ahmad, Y., Ariffin, M. A. M., Sarbini, N. N., et al. (2021). Experimental and Numerical Evaluations of Composite concrete-to-concrete Interfacial Shear Strength under Horizontal greatly influence the interfacial shear capacity and the propagation of the stress wave in the Old - New concrete. The change of WPEI in the received signals is in direct relation to the severity of the Old - New concrete interfacial bond slip, and demonstrates whether the PZT-based active sensing method is feasible or not in terms of monitoring shear-induced Old - New concrete interfacial bond slip.

In future studies, the authors will design better loading methods to ensure that the shear load can be better applied during the whole experiment process. And the Old - New interfacial bond slip of real engineering components including the beams and columns will be further researched in detail. In addition, the influence of different ages, composite stress states, and steel anchoring forms on Old - New concrete interfacial bond slip would be considered. Moreover, the active sensing method combined with the method of big data, artificial intelligence would be employed to achieve intelligent monitoring of old-new concrete interfacial bond slip.

\section{DATA AVAILABILITY STATEMENT}

The original contributions presented in the study are included in the article/Supplementary Material, further inquiries can be directed to the corresponding author.

\section{AUTHOR CONTRIBUTIONS}

JJ developed the original idea. JD and JJ designed the experiments. YC and JJ conducted the experiments. JJ and YC analyzed the data. JJ and YC wrote the original draft. JD made critical revision to the paper.

\section{FUNDING}

This research was financially supported by the National key research and development program "Search and rescue techniques for earthquake casualties in catastrophic municipal urban areas" (PID: 2018YFC1504404) and Science for Earthquake Resilience of China Earthquake Administration (Grant No. XH19043Y and XH20040YSX). and normal Stresses. PLoS ONE 16 (5), e0252050. doi:10.1371/ journal.pone. 0252050

Annamdas, V. G. M., and Soh, C. K. (2017). Load Monitoring Using a Calibrated Piezo Diaphragm Based Impedance Strain Sensor and Wireless Sensor Network in Real Time. Smart Mater. Struct. 26 (4), 045036. doi:10.1088/1361-665x/aa5f40 Bajer, M., and Barnat, J. (2012). The Glue-concrete Interface of Bonded Anchors. Construction Building Mater. 34, 267-274. doi:10.1016/j.conbuildmat.2012.02.030

Barnaf, J., Bajer, M., and Vyhnankova, M. (2012). Bond Strength of Chemical Anchor in High-Strength Concrete. Proced. Eng. 40, 38-43. doi:10.1016/ j.proeng.2012.07.052

Bhalla, S., and Kaur, N. (2018). Prognosis of Low-Strain Fatigue Induced Damage in Reinforced concrete Structures Using Embedded Piezo-Transducers. Int. J. Fatigue 113, 98-112. doi:10.1016/j.ijfatigue.2018.04.002 
Bouazaoui, L., and Li, A. (2008). Analysis of Steel/concrete Interfacial Shear Stress by Means of Pull Out Test. Int. J. Adhes. Adhesives 28 (3), 101-108. doi:10.1016/ j.ijadhadh.2007.02.006

Brencich, A. (2015). A post-installed Insert for Pull-Out Tests on concrete up to 70 $\mathrm{MPa}$. Construction Building Mater. 95, 788-801. doi:10.1016/ j.conbuildmat.2015.07.055

Coles, A., de Castro, B. A., Andreades, C., Baptista, F. G., Meo, M., and Ciampa, F. (2020). Impact Localization in Composites Using Time Reversal, Embedded PZT Transducers, and Topological Algorithms. Front. Built Environ. 6 (27). doi:10.3389/fbuil.2020.00027

Cook, R. A., Dorrer, G. T., and Klingner, R. E. (1993). Bond Stress Model for Design of Adhesive Anchors. Sj 90 (5), 514-524. doi:10.14359/3945

Cook, R. A. (1992). Load-Deflection Behavior of Cast-In-Place and Retrofit Concrete Anchors. Sj 89 (6), 639-649. doi:10.14359/4134

Diab, A. M., Abd Elmoaty, A. E. M., and Tag Eldin, M. R. (2017). Slant Shear Bond Strength between Self Compacting concrete and Old concrete. Construction Building Mater. 130, 73-82. doi:10.1016/j.conbuildmat.2016.11.023

Dziendzikowski, M., Niedbala, P., Kurnyta, A., Kowalczyk, K., and Dragan, K. (2018). Structural Health Monitoring of a Composite Panel Based on PZT Sensors and a Transfer Impedance Framework. Sensors 18 (5), 1521. doi:10.3390/s18051521

Fan, S., Li, W., Kong, Q., Feng, Q., and Song, G. (2018). Monitoring of Pin Connection Loosening Using Eletromechanical Impedance: Numerical Simulation with Experimental Verification. J. Intell. Mater. Syst. Structures 29 (9), 1964-1973. doi:10.1177/1045389X18754354

Fang, H., Su, Z., Li, X., Wang, F., and Fu, Y. (2021). Interfacial Bond Performance between Self-Expansion Polymer and concrete. Construction Building Mater. 270, 121459. doi:10.1016/j.conbuildmat.2020.121459

Feng, Q., and Ou, J. (2018). Self-Sensing CFRP Fabric for Structural Strengthening and Damage Detection of Reinforced Concrete Structures. Sensors 18 (12), 4137. doi:10.3390/s18124137

González, F., Fernández, J., Agranati, G., and Villanueva, P. (2018). Influence of Construction Conditions on Strength of post Installed Bonded Anchors. Construction Building Mater. 165, 272-283. doi:10.1016/j.conbuildmat.2017.12.144

Hong, X., Liu, Y., Liufu, Y., and Lin, P. (2018). Debonding Detection in Hidden Frame Supported Glass Curtain Walls Using the Nonlinear Ultrasonic Modulation Method with Piezoceramic Transducers. Sensors 18 (7), 2094. doi:10.3390/s18072094

Hou, S., Cai, C. S. S., and Ou, J. (2009). "FRP Debonding Monitoring Using OTDR Techniques." in Proceedings of the Second International Conference on Smart Materials and Nanotechnology in Engineering, Weihai, China, July 8-11 2009. 7493. doi: $10.1117 / 12.843559$

Hu, G., Tang, L., and Das, R. (2018). General Framework for Modeling Multifunctional Metamaterial Beam Based on a Derived One-Dimensional Piezoelectric Composite Finite Element. J. Aerosp. Eng. 31 (6), 04018088. doi:10.1061/(ASCE)AS.1943-5525.0000920

Hyun-Soo Youm, W. Y. L. S. G. H., and Changbin, J. (2021). Interface Shear Strength between Ultra-high-performance Concrete and Normal-Strength Concrete. Sj 118 (2). doi:10.14359/51729350

Jiang, J., Hei, C., Feng, Q., and Jiang, J. (2019). Monitoring of Epoxy-Grouted Bonding Strength Development between an Anchored Steel Bar and Concrete Using PZT-Enabled Active Sensing. Sensors 19 (9), 2096. doi:10.3390/ s1906137710.3390/s19092096

Ju, Y., Shen, T., and Wang, D. (2020). Bonding Behavior between Reactive Powder concrete and normal Strength concrete. Construction Building Mater. 242, 118024. doi:10.1016/j.conbuildmat.2020.118024

Júlio, E. N. B. S., Branco, F. A. B., Silva, V. D., and Lourenço, J. F. (2006). Influence of Added concrete Compressive Strength on Adhesion to an Existing concrete Substrate. Building Environ. 41 (12), 1934-1939. doi:10.1016/ j.buildenv.2005.06.023

Kong, Q., Robert, R., Silva, P., and Mo, Y. (2016). Cyclic Crack Monitoring of a Reinforced Concrete Column under Simulated Pseudo-dynamic Loading Using Piezoceramic-Based Smart Aggregates. Appl. Sci. 6 (11), 341. doi:10.3390/ app6110341

Kong, Q., and Song, G. (2017). A Comparative Study of the Very Early Age Cement Hydration Monitoring Using Compressive and Shear Mode Smart Aggregates. IEEE Sensors J. 17 (2), 256-260. doi:10.1109/JSEN.2016.2624799
Lee, J.-W. (2021). An Experimental Study on Bolt Looseness Monitoring Using Low-Cost Transfer Impedance Technique. Int. J. Steel Struct. 21 (1), 349-359. doi:10.1007/s13296-020-00442-1

Li, W., Fan, S., Ho, S. C. M., Wu, J., and Song, G. (2017). Interfacial Debonding Detection in Fiber-Reinforced Polymer Rebar-Reinforced concrete Using Electro-Mechanical Impedance Technique. Struct. Health Monit. 17 (3), 461-471. doi:10.1177/1475921717703053

Liang, Y., Li, D., Parvasi, S. M., Kong, Q., Lim, I., and Song, G. (2016). Bond-slip Detection of concrete-encased Composite Structure Using Electro-Mechanical Impedance Technique. Smart Mater. Struct. 25 (9), 095003. doi:10.1088/09641726/25/9/095003

Liu, X., Liu, Y., Wu, T., and Wei, H. (2020). Bond-slip Properties between Lightweight Aggregate concrete and Rebar. Construction Building Mater. 255, 119355. doi:10.1016/j.conbuildmat.2020.119355

Mahrenholtz, P., Eligehausen, R., Hutchinson, T. C., and Hoehler, M. S. (2016). Behavior of Post-Installed Anchors Tested By Stepwise Increasing Cyclic Load Protocols. ACI Struct. J. 113 (5), 997-1008. doi:10.14359/51689023

Maili, C., and Jing, M. (2018). Experimental Study on Shear Behavior of the Interface between New and Old Concrete with Reinforced. KSCE J. Civ Eng. 22 (5), 1882-1888. doi:10.1007/s12205-017-2007-6

Mirmoghtadaei, R., Mohammadi, M., Ashraf Samani, N., and Mousavi, S. (2015). The Impact of Surface Preparation on the Bond Strength of Repaired concrete by Metakaolin Containing concrete. Construction Building Mater. 80, 76-83. doi:10.1016/j.conbuildmat.2015.01.018

Muciaccia, G., Consiglio, A., and Rosati, G. (2018). Creep Behavior of Bonded Anchor under High Sustained Loading at Long Term Temperature. (Cham, Switzerland: Springer International Publishing), 956-964. doi:10.1007/978-3319-59471-2_111

Nicassio, F., Carrino, S., and Scarselli, G. (2020). Non-linear Lamb Waves for Locating Defects in Single-Lap Joints. Front. Built Environ. 6 (45). doi:10.3389/ fbuil.2020.00045

Qasim, O. A. (2020). Different Concrete Types Affecting the Bond Strength and Interfacial Joints between New and Old Concrete. IOP Conf. Ser. Mater. Sci. Eng. 745, 012169. doi:10.1088/1757-899x/745/1/012169

Qin, F., Kong, Q., Li, M., Mo, Y. L., Song, G., and Fan, F. (2015). Bond Slip Detection of Steel Plate and concrete Beams Using Smart Aggregates. Smart Mater. Struct. 24 (11), 115039. doi:10.1088/0964-1726/24/11/115039

Rizzo, P., Spada, A., Degala, S., and Giambanco, G. (2010). Acoustic Emission Monitoring of Chemically Bonded Anchors. J. Nondestruct Eval. 29 (1), 49-61. doi:10.1007/s10921-010-0065-5

Ronald, A. C., and Robert, C. K. (2001). Factors Influencing Bond Strength of Adhesive Anchors. Sj 98 (1). doi:10.14359/10149

Song, X., Wu, Y., Gu, X., and Chen, C. (2015). Bond Behaviour of Reinforcing Steel Bars in Early Age concrete. Construction Building Mater. 94, 209-217. doi:10.1016/j.conbuildmat.2015.06.060

Wang, D., Wu, D., He, S., Zhou, J., and Ouyang, C. (2015). Behavior of postinstalled Large-Diameter Anchors in concrete Foundations. Construction Building Mater. 95, 124-132. doi:10.1016/j.conbuildmat.2015.07.129

Wang, F., Chen, Z., and Song, G. (2020a). Monitoring of Multi-Bolt Connection Looseness Using Entropy-Based Active Sensing and Genetic Algorithm-Based Least Square Support Vector Machine. Mech. Syst. Signal Process. 136, 106507. doi:10.1016/j.ymssp.2019.106507

Wang, W.-w., Dai, J.-g., Li, G., and Huang, C.-k. (2011). Long-Term Behavior of Prestressed Old-New Concrete Composite Beams. J. Bridge Eng. 16 (2), 275-285. doi:10.1061/(ASCE)BE.1943-5592.0000152

Wang, Y., He, M., Sun, L., Wu, D., Wang, Y., and Zou, L. (2020b). Improved Kalman Filtering-Based Information Fusion for Crack Monitoring Using Piezoelectric-Fiber Hybrid Sensor Network. Front. Mater. 7 (300). doi:10.3389/fmats.2020.00300

Wörle, P. (2014). Enhanced Shear Punching Capacity by the Use of post Installed concrete Screws. Eng. Structures 60, 41-51. doi:10.1016/j.engstruct.2013.12.015

Xu, J., Wang, C., Li, H., Zhang, C., Hao, J., and Fan, S. (2018a). Health Monitoring of Bolted Spherical Joint Connection Based on Active Sensing Technique Using Piezoceramic Transducers. Sensors 18 (6), 1727. doi:10.3390/s18061727

Xu, K., Ren, C., Deng, Q., Jin, Q., and Chen, X. (2018b). Real-Time Monitoring of Bond Slip between GFRP Bar and Concrete Structure Using Piezoceramic 
Transducer-Enabled Active Sensing. Sensors 18 (8), 2653. doi:10.3390/ s18082653

Xu, Y., Luo, M., Liu, Q., Du, G., and Song, G. (2019). PZT Transducer Array Enabled Pipeline Defect Locating Based on Time-Reversal Method and Matching Pursuit De-noising. Smart Mater. Struct. 28 (7), 075019. doi:10.1088/1361-665x/ablcc9

Yilmaz, S., Özen, M. A., and Yardim, Y. (2013). Tensile Behavior of post-installed Chemical Anchors Embedded to Low Strength concrete. Construction Building Mater. 47, 861-866. doi:10.1016/j.conbuildmat.2013.05.032

Zeng, L., Parvasi, S. M., Kong, Q., Huo, L., Lim, I., Li, M., et al. (2015). Bond Slip Detection of concrete-encased Composite Structure Using Shear Wave Based Active Sensing Approach. Smart Mater. Struct. 24 (12), 125026. doi:10.1088/ 0964-1726/24/12/125026

Zhang, L., Zheng, Y., Hu, S., Yang, J., and Xia, L. (2020). Identification of Bond-Slip Behavior of GFRP-ECC Using Smart Aggregate Transducers. Front. Mater. 7 (165). doi:10.3389/fmats.2020.00165

Zhou, L., Zheng, Y., Huo, L., Ye, Y., Chen, D., Ma, H., et al. (2020). Monitoring of Bending Stiffness of BFRP Reinforced concrete Beams Using Piezoceramic Transducer Enabled Active Sensing. Smart Mater. Struct. 29 (10), 105012. doi:10.1088/1361-665x/ab936d

Zhou, Z., He, J., Huang, Y., and Ou, J. (2008). "Experimental Investigation of RC Beams Using BOTDA(R)-FRP-OF." in Proceedings of the 19th International Conference on Optical Fibre Sensors, April 15-18 2008, Perth, WA, Australia (Perth, WA, Australia: Proc. SPIE 7004). doi:10.1117/12.787120
Zhu, J., Ho, S. C. M., Patil, D., Wang, N., Hirsch, R., and Song, G. (2017) Underwater Pipeline Impact Localization Using Piezoceramic Transducers. Smart Mater. Struct. 26 (10), 107002. doi:10.1088/1361$665 \mathrm{x} / \mathrm{aa} 80 \mathrm{c} 9$

Conflict of Interest: Author JJ was employed by the company Wuhan Institute of Earthquake Engineering Co., Ltd.

The remaining authors declare that the research was conducted in the absence of any commercial or financial relationships that could be construed as a potential conflict of interest.

Publisher's Note: All claims expressed in this article are solely those of the authors and do not necessarily represent those of their affiliated organizations, or those of the publisher, the editors and the reviewers. Any product that may be evaluated in this article, or claim that may be made by its manufacturer, is not guaranteed or endorsed by the publisher.

Copyright (c) 2021 Jiang, Chen and Dai. This is an open-access article distributed under the terms of the Creative Commons Attribution License (CC BY). The use, distribution or reproduction in other forums is permitted, provided the original author(s) and the copyright owner(s) are credited and that the original publication in this journal is cited, in accordance with accepted academic practice. No use, distribution or reproduction is permitted which does not comply with these terms. 